\title{
Association between arterial stiffness and obstructive sleep apnea in patients with arterial hypertension and continuous positive airway pressure therapy
}

\author{
Yu Sirenko ${ }^{1}$, N Krushynska ${ }^{2}$, O Rekovets ${ }^{1 *}$, O Torbas ${ }^{1}$ and S Kushnir ${ }^{1}$ \\ ${ }^{1}$ National Scientific Center "M.D. Strazhesko Institute of Cardiology", Kyiv, Ukraine \\ ${ }^{2}$ O.O. Bohomolets National Medical University, Kyiv, Ukraine
}

\begin{abstract}
Background: Obstructive Sleep Apnea (OSA), especially severe, is related with fatal and non-fatal cardio-vascular (CV) events. OSA and arterial hypertension $(\mathrm{AH})$ have bidirectional relationship, and this comorbidity is much common and that are associated with elevated cardiovascular disease risk. One of the reasons is an increased arterial stiffness. Aortic pulse wave velocity (PWV) is a highly reproducible noninvasive measure of arterial stiffness recommended in current guidelines for evaluation of cardiovascular risk.

Aim: The aim of the study was to assess the arterial stiffness changes in patients with arterial hypertension (AH) and obstructive sleep apnea (OSA) and possibilities of its correction by continuous positive airway pressure (CPAP)-therapy.

Design: 185 patients with mild and moderate AH (49.8 \pm 0.80 years old) were enrolled in the study and divided into groups: 1 -st group - patients who had OSA ( $n=148)$, 2-nd group - patients without OSA (control group, $n=37$ ). They underwent clinical and special examination: unattended somnography by dualchannel portable monitor device, estimation of daily sleepiness by Epworth Sleepiness Scale, office and ambulatory blood pressure monitoring, echocardiography and applanation tonometry. In 10 months, follow-up study was included 105 patients, who were divided into 4 subgroups: A - patients with moderate to severe OSA on CPAP ( $n=23$ ); B - patients with moderate to severe OSA without CPAP ( $n=29)$; C - patients with mild OSA ( $n=29$ ); D - patients without OSA (controls, $n=24)$. All patients received similar antihypertensive therapy according to $2013 \mathrm{ESH} / \mathrm{ESC}$ Guidelines.

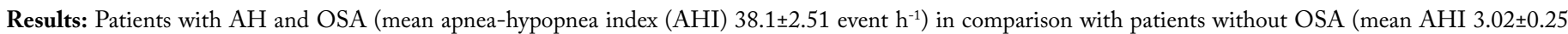
event $\left.\mathrm{h}^{-1}\right)$ had significantly higher body mass index $\left(35.2 \pm 0.57\right.$ vs. $\left.30.6 \pm 0.79 \mathrm{~kg} \mathrm{~m}^{-2}, \mathrm{P}<0.001\right)$, blood glucose level $\left(107.2 \pm 2.2\right.$ vs. $\left.98.0 \pm 2.5 \mathrm{mg} \mathrm{dl} \mathrm{l}^{-1}, \mathrm{P}=0.045\right)$, uric acid level $\left(6.17 \pm 0.1\right.$ vs. $\left.5.5 \pm 0.3 \mathrm{mg} \mathrm{dl}^{-1}, \mathrm{P}=0.048\right)$ and left ventricular mass index (LVMI) $\left(115.8 \pm 2.39\right.$ vs. $\left.104.6 \pm 4.56 \mathrm{~g} \mathrm{~m}^{-2}, \mathrm{P}=0.035\right)$. Also, the patients with $\mathrm{AH}$ and OSA in comparison with patients without OSA had higher carotid-femoral pulse wave velocity (PWVcf) (11.19 \pm 0.20 vs. $10.10 \mathrm{~m} \mathrm{~s}{ }^{-1}$, $\left.\mathrm{P}=0.014\right)$ and central systolic blood pressure (CSBP) $(133.43 \pm 1.67$ vs. $125.22 \pm 3.41 \mathrm{~mm} \mathrm{Hg}, \mathrm{P}=0.027)$. During 10 -month follow-up in patients with AH and OSA on CPAP-therapy there were significantly decrease of PWVcf (from $12.2 \pm 0.63$ to $10.05 \pm 0.43 \mathrm{~m} \mathrm{~s}^{-1}, \mathrm{P}=0.009$ ) with achievement of normal level (<10 m s$\left.{ }^{-1}\right)$ in $60.9 \%$ patients, office systolic blood pressure (from $143.8 \pm 132.7$ to $132.7 \pm 2.33 \mathrm{~mm} \mathrm{Hg} ; \mathrm{P}=0.021$ ) and diastolic blood pressure (from 93.8 \pm 3.31 to $86.0 \pm 3.19 \mathrm{~mm} \mathrm{Hg}$; $\mathrm{P}=0.012$ ) with achievement of target levels. In patients central systolic BP decreased (from $130.3 \pm 3.97$ to $119.7 \pm 2.97 \mathrm{~mm} \mathrm{Hg} ; \mathrm{P}=0.012$ ) and diastolic BP decreased (from $94.7 \pm 3.31$ to $87.1 \pm 2.36$ $\mathrm{mm} \mathrm{Hg}, \mathrm{P}=0.013)$.
\end{abstract}

Conclusion: Combination of continuous positive airway pressure (CPAP)-therapy and antihypertensive treatment improvement of arterial elasticity and helps to achieve target blood pressure in patients with $\mathrm{AH}$ and moderate to severe OSA.

\section{Introduction}

During the last decades obstructive sleep apnea (OSA) has been recognized as an independent risk factor for the development of hypertension and additionally high prevalence of OSA in patients with refractory hypertension was observed. OSA is the disorder of breathing characterized by repetitive interruption of ventilation during sleep caused inadequate tone of airway muscles and collapse of the pharyngeal airway. The pause in respiration associated with ongoing ventilatory effort. Obstructive hypopneas are decreased in size, but not complete cessation of ventilation, associated with fall in oxygen saturation or arousal [1].

The current prevalence of moderate the to severe sleep breathing disorders (AHI, measured as events hour ${ }^{-1}, \geq 15$ ) among 30-49-year-old men is $10 \%$ (95\% confidence interval (CI): 7,12$)$; $17 \%$ (95\% CI: 15,21$)$ among 50-70-year-old men; 3 \% (95 \% CI: 2, 4) among 30-49-year-old women; and $9 \%$ (95\% CI: 7, 11) among 50-70-year-old women [2]. Detection of OSA is extremely important in patients with AH. These two conditions frequently coexist (up to $50 \%$ of patients with $\mathrm{AH}$ have concomitant OSA), and OSA is a widespread contributor for elevated $\mathrm{BP}$ in patients with resistant $\mathrm{AH}$ [3]. OSA can increase cardiovascular risk by initiating or progressing of arterial hypertension, development of atherosclerosis, coronary artery disease, and its complications like

${ }^{\star}$ Correspondence to: Oksana Rekovets, National Scientific Center "M.D. Strazhesko Institute of Cardiology”, Kyiv, Ukraine, E-mail: recovets@ukr.net

Key words: arterial hypertension, obstructive sleep apnea, continuous positive airway pressure, blood pressure, arterial stiffness, pulse wave velocity

Received: November 06, 2020; Accepted: November 30, 2020; Published: December 08, 2020 

therapy

heart failure, arrhythmias, myocardial infarction, and stroke [4]. One of the reasons of it is an increased arterial stiffness. But current data are insufficient because available studies included different categories of patients [5-10].

A diagnosis of OSA may be established by the two recommended methods of objective testing: in-laboratory polysomnography (PSG) and/or (ambulatory) home testing with portable monitors (PM) [11]. PMs may be used to diagnose OSA when utilized as part of a comprehensive sleep evaluation in patients with a high pretest probability of moderate to severe OSA [12].

Breathing with positive airway pressure (PAP) is the treatment of choice for mild, moderate, and severe OSA and should be offered as an option to all patients [12]. Continuous PAP (CPAP) is indicated for the treatment of moderate to severe OSA as standard and mild OSA as option and as an adjunctive therapy to BP lowering treatment in hypertensive patients with OSA [11]. In spite of general use in practice, an impact of CPAP on arterial stiffness changes in those patients is not investigated.

The aim of the study was to assess the arterial stiffness changes in patients with $\mathrm{AH}$ and OSA and possibilities of their correction by CPAP-therapy.

\section{Design}

\section{Subjects}

We enrolled in the study 185 patients with AH $(49.8 \pm 0.80$ years old), 36 (19,5\%) of them were female, and 149 (80,5\%) were male, who were admitted in specialized department of symptomatic hypertension in the National Scientific Center "M.D. Strazhesko Institute of Cardiology", Kyiv, Ukraine. Hypertension was defined as values $>140$ $\mathrm{mm} \mathrm{Hg}$ systolic blood pressure (SBP) and/or $>90 \mathrm{~mm} \mathrm{Hg}$ diastolic blood pressure (DBP) [13] or intake of antihypertensive drugs. We excluded very elderly patients ( $\geq 80$ years), patients with any other secondary form of $\mathrm{AH}$, with other forms of sleep-disordered breathing (chronic obstructive pulmonary disease, asthma, hypoventilation related to neuromuscular disorders, expressed heart failure with a primary referral for Cheyne-Stokes respiration), with myocardial infarction and stroke within 3 months, decompensated diabetes mellitus $\left(\mathrm{HbA}_{1} \mathrm{C}>11 \%\right)$, severe chronic kidney disease (defined as glomerular filtration rate $[\mathrm{GFR}] \leq 30 \mathrm{ml} / \mathrm{min} / 1.73 \mathrm{~m}^{2}$ ), permanent or persistent atrial fibrillation, psychiatric disorders and alcohol abuse.

\section{Measurements}

Epworth Sleepiness Scale: Subjective sleepiness was assessed with the Epworth Sleepiness Scale (ESS), which assessed the tendency to fall asleep during eight typical daytime situations [14]. A level within 0-9 range considered as a normal, and number in the 10-24 range shown an excessive daily sleepiness.

Nocturnal somnography: Sleep time parameters were recorded using dual-channel portable monitor (PM) device (SOMNOcheck micro, Weinmann, Germany) including:

- Nasal respiratory flow via the nose and snoring sounds were recorded by the Respiratory Flow/Snore Nasal Cannula with the pressure sensor in the measurement device by means of pressure fluctuations in the nostrils.

- Blood oxygen saturation $\left(\mathrm{SaO}_{2}\right)$ and the heart rate were measured by means of the pulsoximetric sensor (CMS 50B) and a plethysmogram. Several $\mathrm{SpO}_{2}$ values were fixed for each pulse wave (split pulse wave algorithm).
Data were collected and stored with SOMNOlab-Software. The apnea was defined as a pause of upper airway flow at least 10 seconds in association with oxygen desaturation (>3-4 \%) and/or arousals. Obstructive apnea was defined as cessation of airflow with persistence of thoracoabdominal movements. Hypopnea was defined as a reduction more than $50 \%$ on oro-nasal airflow, lasting more than 10 seconds, associated with oxygen desaturation and/or arousals [15]. Apnoe-hypopnoe index (AHI) was defined as the number of apnea plus hypopnea episodes per hour of sleep. Oxygen desaturation index indicates the number of oxygen desaturation per hour of sleep. The diagnosis of OSA was confirmed in patients with the number of obstructive events (apneas, hypopneas + respiratory event related arousals) more than 15 in hour or greater than 5 in hour in patients who reported any of the following conditions: daytime sleepiness; unintentional sleep episodes during wakefulness; unrefreshing sleep; fatigue; insomnia; waking up breath holding, gasping, or choking; or the bed partner describing loud snoring, breathing interruptions, or both during the patient's sleep [16]. As recommended the severity of OSA was defined as mild when AHI was $\geq 5$ and $<15$, moderate - for $\mathrm{AHI} \geq 15$ and $\leq 30$, and severe - for AHI $>30$ in hour.

\section{Ambulatory blood pressure monitoring (ABPM)}

ABPM was performed by the portable BP measuring device ABPM-04 (Meditech, Hungary) on the nondominant arm, for a $24 \mathrm{~h}$ period according to standard method. Measurements were made at 15 min intervals during the day and every 30 min overnight. For quality control of the method, we considered at least of $70 \%$ successful BP measurement during daytime and night-time periods [13].

\section{Pulse wave analysis}

We used SphygmoCor device (AtCor Medical, Sydney, Australia) for large artery stiffness assessment: radial artery pulse waveforms were recorded with a pressure tonometer with device designated software [17]. Pressure was applied to the radial artery with a probe containing a high-fidelity transducer, through which pulse waves were recorded. Mean values of approximately 10 radial pulse waves were used to generate a central aortic pressure waveform with a validated mathematical transfer function [18]. The augmentation index (AIx) was calculated to standard formula as the difference between the second (P2) and first systolic peak pressure (P1), expressed as percentage of the central pulse blood pressure $(\mathrm{CPBP})$ : Aix $(\%)=[(\mathrm{P} 2-\mathrm{P} 1) / \mathrm{PP}] \times$ 100. All values of AIx were corrected to 75 beats/minute heart rate. Several estimations of AIx were performed on each occasion and the measurement with the highest operator index was used for statistical analysis.

Pulse wave velocity was defined as the velocity at which the pressure wave travels between two points of known distance apart. Standard measurements were performed by recording carotid artery pressure waveform, followed on the femoral (PWVcf) and radial artery (PWVcr), with an ECG signal being recorded simultaneously with SphygmoCor device. PWV was calculated automatically using the arterial path length between the two recording sites and the mean transit time difference.

\section{Echocardiography}

All echocardiographic measurements were performed according to recommended standards of the American Society of Echocardiography by the «Imagic Agile» («Kontron Medical», France). Patients were in the lateral decubitus position. All echocardiographic examinations were performed by the same cardiologist who was blinded to the presence or absence of OSA. Basic measurements of left atrial and ventricular dimensions in diastole and systole, and thicknesses of interventricular 

therapy

septum (IVS), left ventricular posterior wall (LVPW), and calculation of left ventricle mass (LVM) were performed; for calculation of LVM index (LVMI) we used standard formulas: divided LVM by the body surface area [19]. The left ventricular ejection fraction (LVEF) was calculated by the Simpson method as (diastolic volume - systolic volume)/diastolic volume.

\section{CPAP application}

All patients in CPAP subgroup received CPAP titration using a setting device for 1 night. The optimal CPAP pressure for each patient was set at the minimum level of air pressure required to abolish snoring, obstructive respiratory events, and airflow limitation for $95 \%$ of the night. Each patient received standardized instructions when start of the CPAP treatment. Then this fixed optimal pressure was maintained with CPAP machine throughout the study. CPAP adherence and AHI were automatically measured by the built-in CPAP devices' compliance software during the regular examination at follow-up period. Patients are generally considered adequately adherent to their CPAP treatment if the mean CPAP use was at least 5 hours/night.

\section{Protocol}

The study protocol was approved by the Local Ethical Committee of the National Scientific Center "M.D. Strazhesko Institute of Cardiology". All patients signed the informed consent before enrolment in the study. All patients underwent clinical and special examination. They were consequently divided into groups those with OSA $(n=148)$ and patients without OSA (control group, $n=37$ ). All patients were prescribed antihypertensive drugs according to $2013 \mathrm{ESH} / \mathrm{ESC}$ Guidelines for the management of arterial hypertension taking into accounts an individual indications and tolerance of different agents. All patients with moderate to severe OSA were advised to CPAP-therapy, which was titrated in the sleep laboratory to the optimal pressure as described above. Into the 10 months follow-up study were included 105 patients, who were divided into 4 subgroups: A - patients with $\mathrm{AH}$ and OSA on CPAP $(\mathrm{n}=23)$, mean therapeutic pressure $8.3 \pm 1.81 \mathrm{GPa}$; $\mathrm{B}$ - patients with $\mathrm{AH}$ and OSA without CPAP ( $\mathrm{n}=29)$; $\mathrm{C}$ - patients with AH and mild OSA $(n=29)$; D - patients with AH without OSA (control subgroup, $n=24)$.

\section{Statistical analysis}

Data are expressed as means (SEM) if data were normally distributed and as medians (interquartile range) if data were not normally distributed, whereas categorical variables are reported as absolute numbers and percentages. All statistical analyses were performed with SPSS version 21 software (SPSS, Chicago, IL). For baseline comparison between the OSA and control groups and subgroups in terms of patients' characteristics, blood pressure and arterial stiffness data were compared by independent $t$-tests because data were normally distributed. Spearman's rank test was used for correlation analysis. The intragroup changes from baseline to the end of follow-up were assessed with the paired t-test. A P value less than 0.05 was considered to be statistically significant.

\section{Results}

\section{Patient characteristics}

185 patients with arterial hypertension were enrolled into the study. They were divided into 2 groups: OSA group - 148 patients with OSA, indicated by at mean AHI of $38.1 \pm 2.5 \mathrm{~h}^{-1}$, and control group 37 patients without OSA, mean AHI $3.02 \pm 0.25 \mathrm{~h}^{-1}(\mathrm{P}<0.001)$. Patients of both groups were comparable on age, height, total cholesterol level and office systolic blood pressure (SBP) and diastolic blood pressure (DBP). The baseline clinical characteristics of patients from the OSA and control groups are summarized in Table 1 .

Table 1. Patient characteristic at the beginning of the study

\begin{tabular}{|c|c|c|c|}
\hline Variable & OSA group $(n=148)$ & Control group $(n=37)$ & P-value \\
\hline \multicolumn{4}{|l|}{ Clinical characteristics } \\
\hline Age (years) & $50.6 \pm 0.84$ & $46.8 \pm 2.10$ & NS \\
\hline Body mass index $\left(\mathrm{kg} \mathrm{m}^{-2}\right)$ & $35.2 \pm 0.57$ & $30.6 \pm 0.79$ & $<0.001$ \\
\hline Body weight $(\mathrm{kg})$ & $107.2 \pm 1.79$ & $93.4 \pm 2.54$ & $<0.001$ \\
\hline \multicolumn{4}{|l|}{ Vascular parameters } \\
\hline Heart rate (b.p.m) & $69.2 \pm 0.94$ & $69.1 \pm 1.91$ & NS \\
\hline Systolic blood pressure (mm Hg) & $145.6 \pm 1.67$ & $138.4 \pm 3.66$ & NS \\
\hline Diastolic blood pressure (mm Hg) & $93.6+ \pm 1.18$ & $89.1 \pm 2.11$ & NS \\
\hline 24-h systolic blood pressure (mm Hg) & $141.0 \pm 1.64$ & $131.6 \pm 2.24$ & 0.005 \\
\hline 24-h diastolic blood pressure (mm Hg) & $84.7 \pm 1.11$ & $79.5 \pm 1.61$ & 0.024 \\
\hline Pulse wave velocity carotid-femoral $\left(\mathrm{m} \mathrm{s}^{-1}\right)$ & $11.19 \pm 0.20$ & $10.10 \pm 0.41$ & 0.014 \\
\hline Central systolic blood pressure (mm Hg) & $133.4 \pm 1.67$ & $125.2 \pm 3.41$ & 0.027 \\
\hline \multicolumn{4}{|l|}{ Heart parameters } \\
\hline 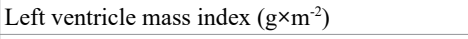 & $115.8 \pm 2.39$ & $104.6 \pm 4.56$ & 0.035 \\
\hline Left ventricle mass $(\mathrm{g})$ & $262.5 \pm 6.44$ & $227.0 \pm 11.12$ & 0.011 \\
\hline \multicolumn{4}{|l|}{ Sleep data } \\
\hline Apnea-hypopnea index (event $\mathrm{h}^{-1}$ ) & $38.1 \pm 2.51$ & $3.02 \pm 0.25$ & $<0.001$ \\
\hline Epworth Sleepiness Scale score & $9.76 \pm 0.46$ & $6.81 \pm 0.64$ & 0.003 \\
\hline Lowest $\mathrm{SpO}_{2}$ during sleep (\%) & $74.0 \pm 1.07$ & $84.8 \pm 0.71$ & $<0.001$ \\
\hline Desaturation index $\left(\right.$ event $\left.\times \mathrm{h}^{-1}\right)$ & $34.0 \pm 2.63$ & $2.73 \pm 0.41$ & $<0.001$ \\
\hline Snoring (\%) & $31.6 \pm 2.21$ & $13.0 \pm 3.79$ & $<0.001$ \\
\hline \multicolumn{4}{|l|}{ Blood biochemistry } \\
\hline Creatinine $\left(\mathrm{mg} \times \mathrm{dl}^{-1}\right)$ & $0.92 \pm 0.03$ & $0.98 \pm 0.02$ & NS \\
\hline Total cholesterol $\left(\mathrm{mg} \times \mathrm{dl}^{-1}\right)$ & $201.4 \pm 4.6$ & $218.8 \pm 10.8$ & NS \\
\hline Triglycerides $\left(\mathrm{mg} \times \mathrm{dl}^{-1}\right)$ & $270.4 \pm 113.8$ & $200.4 \pm 60.4$ & NS \\
\hline Fasting blood glucose $\left(\mathrm{mg} \times \mathrm{dl}^{-1}\right)$ & $107.2 \pm 2.2$ & $98.0 \pm 2.5$ & 0.045 \\
\hline Uric acid $\left(\mathrm{mg} \times \mathrm{dl}^{-1}\right)$ & $6.17 \pm 0.1$ & $5.5 \pm 0.3$ & 0.048 \\
\hline
\end{tabular}

Unless indicated otherwise, data are given as the mean \pm standard error of the mean (SEM); $\mathrm{SpO}_{2}$ - arterial oxygen saturation, NS - nonsignificant. 

therapy

Patients in the OSA group had a higher BMI $(\mathrm{P}<0.001)$, uric acid level $(\mathrm{P}=0.048)$, fasting glucose level $(\mathrm{P}=0.045)$, prevalence of diabetes mellitus $(\mathrm{P}<0.02)$ and ESS score $(\mathrm{P}=0.003)$ in comparison with the control group.

Patients of both groups had similar office blood pressure levels (SBP $145.6 \pm 1.67$ vs $138.4 \pm 3.66 \mathrm{~mm} \mathrm{Hg}, \mathrm{P}=0.057$ and DBP $93.6+ \pm 1.18$ vs. $89.1 \pm 2.11 \mathrm{~mm} \mathrm{Hg}, \mathrm{P}=0.073$ ), but significantly higher 24 -h systolic and diastolic blood pressure. We suggest that in the study some patients with OSA had masked arterial hypertension.

Baseline patients in the OSA group had a higher PWVcf (on $1.09 \pm 0.44 \mathrm{~m} / \mathrm{s}, \mathrm{P}=0.014$ ) and central SBP (on $8.22 \pm 3.68 \mathrm{~mm} \mathrm{Hg}$, $\mathrm{P}=0.027)$ in comparison with those without OSA. In the patients of control group $\mathrm{PWVcf}$ was independently correlated with age $(B=0.347$; $\mathrm{P}=0.003$ ), but at the same time no correlations were found in OSA patients. Central SBP in OSA patients was independently associated with left atrium diameter $(\beta=0.014 ; \mathrm{P}=0.016)$, LVM $(\beta=-0.036$; $\mathrm{P}=0.029)$ and central augmented pressure $(\mathrm{AuP})(\beta=0.087 ; \mathrm{P}=0.022)$. In the patients without OSA such correlations were not revealed.

After the multivariable regressive analysis the following results were obtained. Daytime sleepiness in OSA patients was associated with structural remodeling of the left ventricle myocardium and more expressed arterial stiffness: ESS score was independently correlated with snoring duration $(\beta=-0.008 ; P=0.021)$, interventricular septum thickness $(\beta=0.023 ; \mathrm{P}=0.026)$, LVMI $(\beta=-0.037 ; \mathrm{P}=0.039)$ and indexes of central pulse wave: ejection duration $(E D)(\beta=-0.020 ; \mathrm{P}<0.001)$ and subendocardial viability ratio (SEVR) $(\beta=-0.224 ; \mathrm{P}=0.012)$. Nocturnal hypoxemia in OSA patients was associated with increased aortic stiffness and higher central blood pressure: desaturation index was independently correlated with Aix $(\beta=4.167 ; \mathrm{P}=0.009)$, Aix75 ( $\beta=-$ 3.929; $\mathrm{P}=0.006)$ and central DBP $(\beta=0.151 ; \mathrm{P}=0.004)$.

Moderate to severe OSA was diagnosed in 107 patients, who were recommended CPAP-therapy. 59 patients ( $55.1 \%$ of them) received CPAP with mean therapeutic pressure $7.87 \pm 0.23 \mathrm{GPa}$; minimal pressure - 4.0 $\mathrm{GPa}$, maximal pressure - $12.0 \mathrm{GPa}$, median - 8.0 $\mathrm{GPa}$. After regressive analysis was founded that adherence to CPAP was independently associated with body mass $(B=0.346 ; p=0.005)$, desaturation index $(B=0.432 ; p=0.010)$ and snoring duration $(B=0.369$; $\mathrm{p}<0.001)$. After 10 months period data of 23 patients who underwent CPAP were analyzed because 36 from 59 patients refused from CPAPtherapy because of different reasons.

105 patients were included into the 10 months follow-up study (51.96 \pm 1.04 years old, female $22(21 \%)$. All of them were divided into 4 subgroups: A - patients with AH with OSA on CPAP-therapy $(n=23)$; $\mathrm{B}$ - patients with AH and OSA without CPAP $(n=29) ; \mathrm{C}$ - patients with $\mathrm{AH}$ and mild OSA ( $\mathrm{n}=29)$; $\mathrm{D}$ - patients with AH without OSA (control subgroup, $\mathrm{n}=24$ ). They received similar drug treatment, that included ACE inhibitors (55 patients, $52.4 \%$ ), calcium antagonists (51 patients, $48.6 \%$ ), beta-blockers (66 patients, $62.9 \%$ ), diuretics ( 80 patients, $76.2 \%$ ), angiotensin receptor blockers (44 patients, $41.9 \%$ ), centrally acting agents ( 8 patients, $7.6 \%)$, alpha-receptor blockers ( 2 patients, $1.9 \%)$, mineralocorticoid receptor antagonists (7 patients, $6.7 \%$ ). Characteristics patient of subgroups at the beginning of the study are presented in the Tables 2 and 3.

Patients with CPAP-therapy (Subgroup A) have more AHI, desaturation index and lower $\mathrm{SpO} 2$ mean and $\mathrm{SpO} 2$ lowest. Because they had severe obstructive sleep apnea, which strongly required positive airway pressure therapy.
But office BP, central BP, age, BMI, PWV was not difference between subgroup $\mathrm{A}$ and $\mathrm{B}$. Thus, patients with $\mathrm{AH}$ and OSA of subgroups $\mathrm{A}$ and $\mathrm{B}$ were comparable on clinical characteristics, especially age, $\mathrm{BP}$ and received similar antihypertensive treatment.

Patients with mild OSA (Subgroup C) and controls (Subgroup D) also were comparable on their initial demographic and clinical parameters (age, BP - office SBP 143.5 $\pm 3.8 \mathrm{mmm} \mathrm{Hg} v s .140 .3 \pm 4.9 \mathrm{~mm}$ Hg; office DBP $89.0 \pm 2.7 \mathrm{~mm} \mathrm{Hg}$ vs. $91.0 \pm 2.8 \mathrm{~mm} \mathrm{Hg}$ ) and vascular characteristics (PWV, central BP - SBP 132,83 $\pm 3,65 \mathrm{~mm} \mathrm{Hg} v$. $128,38 \pm 4,66 \mathrm{~mm} \mathrm{Hg})$, except sleep data: higher AHI $(9.1 \pm 0.51$ vs. 3.2 \pm 0.28 event hour $\left.{ }^{-1}\right)$, higher desaturation index $(5.33 \pm 0.80$ vs. $2.75 \pm 0.56$ event hour $\left.{ }^{-1}\right)$, in Subgroup C vs. Subgroup D.

\section{Effects of CPAP}

The effects of CPAP therapy on measured parameters and sleep data are summarized in Table 4.

CPAP therapy in the combination with antihypertensive treatment had decreased office BP with achievement of target SBP values in $65.2 \%$ patients and DBP - in $69.6 \%$ patients and promoted heart rate lowering (on $7.7 \pm 2.82$ b.p.m). Furthermore, after 10 months of treatment patients in the CPAP subgroup demonstrated a marked improvement in arterial elasticity with significant lowering PWVcf (from $12.2 \pm 0.63$ $\mathrm{m} \mathrm{s}^{-1}$ to $\left.10.05 \pm 0.43 \mathrm{~m} \mathrm{~s}^{-1} ; \mathrm{P}=0.009\right)$ with achievement of normal values $\left(<10 \mathrm{~m} \mathrm{~s}^{-1}\right)$ in $14(60.9 \%)$ patients. Changes in central pressure were comparable with changes in office $\mathrm{BP}$ with significant decrease in CSBP (on $10.5 \pm 3.84 \mathrm{~mm} \mathrm{Hg} ; \mathrm{P}=0.012$ ) and CDBP (on $7.61 \pm 2.82 \mathrm{~mm} \mathrm{Hg}$; $\mathrm{P}=0.013)$. Similar significant improvement was noted for the indices of myocardial perfusion: increase of SEVR $(\mathrm{P}=0.006)$ and reduction of $\mathrm{ED}(\mathrm{P}=0.007)$.

PWVcf reduced more marked in those patients with its initially higher level. After multifactorial regression analysis an absolute value of reduction in $\operatorname{AuP}(B=0.266 ; \mathrm{P}<0.001)$, initial serum level of uric acid $(\beta=-0.347 ; \mathrm{P}=0.028)$, female sex $(\beta=-0.584 ; \mathrm{P}=0.001)$ and initial $\mathrm{AIx} 75$ $(B=0.667 ; P=0.001)$ were identified as independent factors contributing the decreasing in CSBP after 10 months of CPAP in combination with antihypertensive treatment.

As distinguished from subgroup A, in patients of subgroup $B(n=29)$ systolic BP also significantly had decreased (on $9.21 \pm 4.10 \mathrm{~mm} \mathrm{Hg}$, from $151.1 \pm 4.59$ to $141.9 \pm 4.12 \mathrm{~mm} \mathrm{Hg} ; \mathrm{P}=0.033$ ), but its mean level exceeded target level $(<140 \mathrm{~mm} \mathrm{Hg})$ at the end of follow-up period. Target values for SBP were achieved in 17 (58.6\%) patient and in 13 (44.8\%) patients for DBP. Dynamics of arterial elasticity in patients of subgroup B was opposite to patients of subgroup A: PWVcf significantly increased (on $1.06 \pm 0.48 \mathrm{~m} \mathrm{~s}^{-1}$; from $11.17 \pm 0.47$ to $12.15 \pm 0.49 \mathrm{~m} \mathrm{~s}^{-1}, \mathrm{P}=0.036$ ) (Figure 1). In patients with $\mathrm{AH}$ and OSA with CPAP-therapy PWVcf level exceeded normal value $\left(<10 \mathrm{~m} \mathrm{~s}^{-1}\right)$ in $21(75.9 \%)$ patients. Significant changes in other hemodynamic parameters were not found. Initial PWVcf level $(B=1.098 ; \mathrm{P}<0.001)$ was as independent factors increases in PWVcf dynamics after 10 months of follow-up.

In patients of $\mathrm{C}$ subgroup $(\mathrm{n}=29)$ during 10 months of antihypertensive treatment dynamics of office BP was not noted, we observed nonsignificant increase in SBP (from 143.45 \pm 3.77 to $145.93 \pm 3.20 \mathrm{~mm}, 0.58$ ) and DBP (from $89.03 \pm 2.70$ to $90.31 \pm 2.68 \mathrm{~mm}$ $\mathrm{Hg}, \mathrm{P}=0.687)$. At the end of follow-up SBP exceeded target level in 18 (62.1\%) patients and DBP exceeded target level in 17 (58.6\%) patients. PWVcf significantly increased (on $1.14 \pm 0.44 \mathrm{~m} \mathrm{~s}^{-1}$, from $10.94 \pm 0.37$ to $\left.12.18 \pm 0.49 \mathrm{~m} \mathrm{~s}^{-1}, \mathrm{P}=0.015\right)$. Initial AuP level $(\beta=1.774 ; \mathrm{P}=0.031)$, age $(B=0.867 ; P=0.003)$ and initial Aix value $(B=-1.507 ; P=0.043)$ were 
Sirenko Y (2020) Association between arterial stiffness and obstructive sleep apnea in patients with arterial hypertension and continuous positive airway pressure therapy

Table 2. Characteristics of the patient with moderate to severe OSA with (subgroup A) and without (subgroup B) CPAP at the beginning of the study

\begin{tabular}{|c|c|c|c|}
\hline Variables & $\begin{array}{c}\text { Subgroup A } \\
(\mathbf{n}=\mathbf{2 3})\end{array}$ & $\begin{array}{c}\text { Subgroup B } \\
(\mathrm{n}=29)\end{array}$ & P-value \\
\hline \multicolumn{4}{|l|}{ Clinical parameters } \\
\hline Age (years) & $50.6 \pm 1.87$ & $54.2 \pm 1.59$ & NS \\
\hline Body mass (kg) & $118.7 \pm 4.80$ & $105.1 \pm 3.52$ & 0.018 \\
\hline Body mass index $\left(\mathrm{kg} \times \mathrm{m}^{-2}\right)$ & $37.7 \pm 1.42$ & $34.8 \pm 1.11$ & NS \\
\hline Fasting blood glucose $\left(\mathrm{mg} \times \mathrm{dl}^{-1}\right)$ & $112.6 \pm 4.7$ & $112.2 \pm 6.8$ & NS \\
\hline Uric acid $\left(\mathrm{mg} \times \mathrm{dl}^{-1}\right)$ & $6.25 \pm 0.29$ & $6.0 \pm 0.37$ & NS \\
\hline Systolic blood pressure (mm Hg) & $143.8 \pm 4.10$ & $151.1 \pm 4.59$ & NS \\
\hline Diastolic blood pressure (mm Hg) & $93.8 \pm 3.31$ & $95.1 \pm 2.73$ & NS \\
\hline Left ventricle mass index $\left(\mathrm{g} \times \mathrm{m}^{-2}\right)$ & $109.6 \pm 5.72$ & $116.3 \pm 5.69$ & NS \\
\hline Heart rate (b. p. m.) & $74.9 \pm 2.94$ & $65.6 \pm 1.78$ & 0.002 \\
\hline \multicolumn{4}{|l|}{ Sleep data } \\
\hline AHI, event hour ${ }^{-1}$ & $64,2 \pm 6,8$ & $33,37 \pm 3,15$ & $<0.001$ \\
\hline Lowest $\mathrm{SpO}_{2}, \%$ & $64,96 \pm 3,15$ & $75,10 \pm 2,06$ & 0.009 \\
\hline Mean $\mathrm{SpO}_{2}, \%$ & $88,97 \pm 1,18$ & $92,6 \pm 0,46$ & 0.003 \\
\hline Desaturation index, event hour ${ }^{-1}$ & $61,30 \pm 6,91$ & $23,94 \pm 3,27$ & $<0.001$ \\
\hline \multicolumn{4}{|l|}{ Pulse wave analysis } \\
\hline PWVcf, $\left(\mathrm{m} \times \mathrm{s}^{-1}\right)$ & $12,22 \pm 0,63$ & $11,17 \pm 0,47$ & NS \\
\hline PWVcr, $\mathrm{m} \times \mathrm{s}^{-1}$ ) & $9,43 \pm 0,30$ & $9,03 \pm 0,29$ & NS \\
\hline Augmented pressure, $(\mathrm{mm} \mathrm{Hg})$ & $6,48 \pm 1,24$ & $12,21 \pm 1,46$ & 0.005 \\
\hline Central systolic BP, $(\mathrm{mm} \mathrm{Hg})$ & $130,26 \pm 3,97$ & $140,21 \pm 4,52$ & NS \\
\hline Central diastolic BP, $(\mathrm{mm} \mathrm{Hg})$ & $94,70 \pm 3,31$ & $95,39 \pm 2,78$ & NS \\
\hline Central pulse BP, $(\mathrm{mm} \mathrm{Hg})$ & $35,26 \pm 2,50$ & $44,46 \pm 3,24$ & 0.035 \\
\hline AIx, $(\%)$ & $16,09 \pm 2,43$ & $26,54 \pm 2,28$ & 0.003 \\
\hline AIx 75, (\%) & $15,87 \pm 2,12$ & $21,60 \pm 2,47$ & NS \\
\hline Ejection duration, (\%) & $37,26 \pm 0,67$ & $34,42 \pm 0,79$ & 0.009 \\
\hline SEVR, $(\%)$ & $147,87 \pm 4,19$ & $163,88 \pm 5,59$ & 0.028 \\
\hline
\end{tabular}

Unless indicated otherwise, data are given as the mean \pm standard error of the mean (SEM), NS - non significant.

Table 3. Characteristics of the patients of subgroups $C$ and $D$ at the beginning of the study

\begin{tabular}{|c|c|c|c|}
\hline Variables & $\begin{array}{c}\text { Subgroup C } \\
(n=29)\end{array}$ & $\begin{array}{c}\text { Subgroup D } \\
(n=24)\end{array}$ & P-value \\
\hline \multicolumn{4}{|c|}{ Clinical parameters } \\
\hline Age (years) & $53.7 \pm 2.14$ & $48.5 \pm 2.6$ & NS \\
\hline Body mass (kg) & $95.5 \pm 3.87$ & $95.25 \pm 3.51$ & NS \\
\hline Body mass index $\left(\mathrm{kg} \times \mathrm{m}^{-2}\right)$ & $32.1 \pm 1.09$ & $31.1 \pm 1.03$ & NS \\
\hline Fasting blood glucose $\left(\mathrm{mg} \times \mathrm{dl}^{-1}\right)$ & $113.4 \pm 4.72$ & $113.01 \pm 6.9$ & NS \\
\hline Uric acid $\left(\mathrm{mg} \times \mathrm{dl}^{-1}\right)$ & $6.25 \pm 0.29$ & $6.0 \pm 0.37$ & NS \\
\hline Systolic blood pressure $(\mathrm{mm} \mathrm{Hg})$ & $143.5 \pm 3.8$ & $140.3 \pm 4.9$ & NS \\
\hline Diastolic blood pressure (mm Hg) & $89.0 \pm 2.7$ & $91.0 \pm 2.8$ & NS \\
\hline Left ventricle mass index $\left(\mathrm{g} \times \mathrm{m}^{-2}\right)$ & $111.5 \pm 5.27$ & $104.7 \pm 5.39$ & NS \\
\hline Heart rate (b. p. m.) & $65.7 \pm 1.8$ & $64.8 \pm 1.9$ & NS \\
\hline \multicolumn{4}{|c|}{ Sleep data } \\
\hline AHI, event hour ${ }^{-1}$ & $9.1 \pm 0.51$ & $3.2 \pm 0.28$ & $<0.001$ \\
\hline Lowest $\mathrm{SpO}_{2}, \%$ & $81.3 \pm 1.07$ & $85.0 \pm 0.89$ & 0.032 \\
\hline Mean $\mathrm{SpO}_{2}, \%$ & $93.8 \pm 0.31$ & $94.5 \pm 0,29$ & NS \\
\hline Desaturation index, event hour ${ }^{-1}$ & $5.33 \pm 0.80$ & $2.75 \pm 0.56$ & 0.013 \\
\hline \multicolumn{4}{|c|}{ Pulse wave analysis } \\
\hline PWVcf, $\mathrm{m} \mathrm{s}^{-1}$ & $10,94 \pm 0,37$ & $10,29 \pm 0,37$ & NS \\
\hline PWVcr, $\mathrm{m} \times \mathrm{s}^{-1}$ & $9,00 \pm 0,24$ & $8,91 \pm 0,36$ & NS \\
\hline Augmented pressure, $\mathrm{mm} \mathrm{Hg}$. & $9,90 \pm 1,28$ & $8,71 \pm 1,39$ & NS \\
\hline Central systolic BP, $\mathrm{mm} \mathrm{Hg}$ & $132,83 \pm 3,65$ & $128,38 \pm 4,66$ & NS \\
\hline Central diastolic BP, $\mathrm{mm} \mathrm{Hg}$ & $90,21 \pm 2,73$ & $92,00 \pm 2,89$ & NS \\
\hline Central pulse $\mathrm{BP}, \mathrm{mm} \mathrm{Hg}$ & $42,62 \pm 2,16$ & $36,38 \pm 2,77$ & NS \\
\hline AIx, \% & $22,17 \pm 2,37$ & $22,28 \pm 2,16$ & NS \\
\hline AIx $75, \%$ & $18,19 \pm 2,48$ & $16,87 \pm 1,98$ & NS \\
\hline Ejection duration, $\%$ & $33,92 \pm 0,77$ & $33,43 \pm 0,74$ & NS \\
\hline SEVR, \% & $166,19 \pm 6,21$ & $175,70 \pm 5,85$ & NS \\
\hline
\end{tabular}

Unless indicated otherwise, data are given as the mean \pm standard error of the mean (SEM), NS - non significant. 
Sirenko Y (2020) Association between arterial stiffness and obstructive sleep apnea in patients with arterial hypertension and continuous positive airway pressure therapy

identified as independent factors contributing to increase in PWVcf after 10 months of follow-up.

In patients of D subgroup $(n=24)$ dynamics in office BP was nonsignificant but mean SBP value had achieved target level (from $140.29 \pm 4.92$ to $138.50 \pm 4.31 \mathrm{~mm} \mathrm{Hg} ; \mathrm{P}=0.643)$, and $\mathrm{DBP}$ slightly exceeded target level (from $90.59 \pm 2.79$ to $90.92 \pm 2.99 \mathrm{~mm} \mathrm{Hg} ; \mathrm{P}=0.990$ ) at the end of follow-up. Target levels of office BP were achieved in 15 (62.5\%) patients for SBP and in $13(54.2 \%)$ patients for DBP. PWVcf decreased nonsignificantly (on $0.49 \pm 0.40 \mathrm{~m} \mathrm{~s}^{-1}$, from $10.29 \pm 0.37$ to $\left.9.80 \pm 0.45 \mathrm{~m} \mathrm{~s}^{-1}, \mathrm{P}=0.228\right)$ with achieving normal value $\left(<10 \mathrm{~m} \mathrm{~s}^{-1}\right)$. Its normal level was noted in 14 (58.3\%) patients. Dynamics of PWVcf did not significantly correlate with any other factors (Table 5).
As can be seen from the table 5 changes in the elasticity of the vascular wall were different in different subgroups. Thus, in a subgroup A of patients on CPAP therapy there was a significant improvement in the elasticity of the vascular wall by reducing PWVcf after 10 months of CPAP therapy from $12.22 \pm 0.63 \mathrm{~m} / \mathrm{s}-1$ to $10.05 \pm 0.43 \mathrm{~m} / \mathrm{s}^{-1}, \mathrm{p}=0.009$.

At the same time, patients in Subgroup B with AH and OSA moderate and sever after 10 months of drug therapy PWVcf increased from $11,17 \pm 0.47 \mathrm{~m} \mathrm{~s}^{-1}$ to $12.15 \pm 0.49 \mathrm{~m} \mathrm{~s}^{-1} \mathrm{p}=0,036$. The same situation was in Subgroup C in patients with mild OSA and AH PWVcf was increased from $10.94 \pm 0.37 \mathrm{~m} / \mathrm{s}^{-1}$ to $12.18 \pm 0.49 \mathrm{~m} / \mathrm{s}^{-1} \mathrm{p}=0.015$. In Subgroup D (controls) was not different PWVcf.

Table 4. Changes in hemodynamic parameters after 10 months treatment with CPAP in patients with AH and moderate to severe OSA.

\begin{tabular}{|c|c|c|c|}
\hline Variables & $\begin{array}{l}\text { Before } \\
(n=23)\end{array}$ & $\begin{array}{c}\text { After } \\
(\mathbf{n}=\mathbf{2 3})\end{array}$ & P-value \\
\hline Systolic blood pressure, $\mathrm{mm} \mathrm{Hg}$ & $143.8 \pm 4.10$ & $132.7 \pm 3.19$ & 0.021 \\
\hline Diastolic blood pressure, $\mathrm{mm} \mathrm{Hg}$ & $93.8 \pm 3.31$ & $86.0 \pm 2.33$ & 0.012 \\
\hline Heart rate, b.p.m. & $74.9 \pm 2.94$ & $67.2 \pm 3.19$ & 0.012 \\
\hline PWVcf, $\mathrm{m} \times \mathrm{s}^{-1}$ & $12.22 \pm 0.63$ & $10.05 \pm 0.43$ & 0.009 \\
\hline PWVcr, $\mathrm{m} \times \mathrm{s}^{-1}$ & $9.43 \pm 0.30$ & $8.71 \pm 0.31$ & NS \\
\hline Central systolic BP, $\mathrm{mm} \mathrm{Hg}$ & $130.3 \pm 3.97$ & $119.7 \pm 2.97$ & 0.012 \\
\hline Central diastolic BP, $\mathrm{mm} \mathrm{Hg}$ & $94.7 \pm 3.31$ & $87.1 \pm 2.36$ & 0.013 \\
\hline Central pulse BP, mm Hg & $35.3 \pm 2.50$ & $33.7 \pm 2.08$ & NS \\
\hline Augmented pressure, $\mathrm{mm} \mathrm{Hg}$. & $6.48 \pm 1.24$ & $6.39 \pm 1.42$ & NS \\
\hline AIx, \% & $16.09 \pm 2.43$ & $17.30 \pm 3.60$ & NS \\
\hline AIx $75, \%$ & $15.87 \pm 2.12$ & $13.52 \pm 2.99$ & NS \\
\hline Ejection duration, $\%$ & $37.3 \pm 0.67$ & $34.5 \pm 1.09$ & 0.007 \\
\hline SEVR, $\%$ & $147.9 \pm 4.19$ & $168.2 \pm 7.39$ & 0.006 \\
\hline AHI, event $\times \mathrm{h}^{-1}$ & $64.2 \pm 6.81$ & $3.1 \pm 0.65$ & $<0.001$ \\
\hline Lowest $\mathrm{SpO}_{2}, \%$ & $65.0 \pm 3.15$ & $85.8 \pm 0.91$ & $<0.001$ \\
\hline Mean $\mathrm{SpO}_{2}, \%$ & $89.0 \pm 1.18$ & $95.5 \pm 0.22$ & $<0.001$ \\
\hline Desaturation index, event $\times \mathrm{h}^{-1}$ & $61.3 \pm 6.91$ & $8.0 \pm 1.42$ & $<0.001$ \\
\hline
\end{tabular}

Unless indicated otherwise, data are given as the mean \pm standard deviation of the mean (SEM), NS - non significant; $\mathrm{AHI}$ - apnea-hypopnea index; SpO 2 - arterial oxygen saturation.

Table 5. Changes PWVcf over 10 months treatment in patients' subgroups A, B, C, D.

\begin{tabular}{|c|c|c|c|}
\hline PWVcf, $\mathrm{m} \mathrm{s}^{-1}$ & Before & After 10 month & P-value \\
\hline Subgroup A $(\mathrm{n}=23)$ & $12.22 \pm 0.63$ & $10.05 \pm 0.43$ & $12.15 \pm 0.49$ \\
\hline Subgroup B $(\mathrm{n}=29)$ & $11.17 \pm 0.47$ & $12.18 \pm 0.49$ & 0.036 \\
\hline Subgroup C $(\mathrm{n}=29)$ & $10.94 \pm 0.37$ & $9.80 \pm 0.45$ \\
\hline Subgroup D $(\mathrm{n}=24)$ & $10.29 \pm 0.37$ & 0.015 \\
\hline
\end{tabular}

NS - not significant

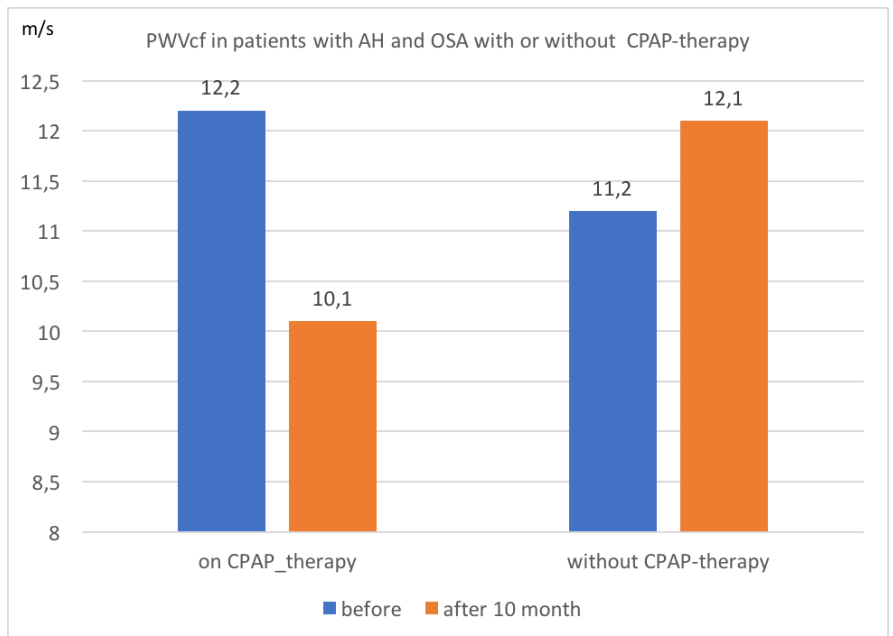

Figure 1. Changes PWVcf in patients with $\mathrm{AH}$ and OSA after 10 months with and without CPAP-therapy 

therapy

We could say that treatment AH with OSA on CPAP therapy combination with $\mathrm{AH}$ drugs leads to improve elasticity vascular wall.

\section{Discussion}

Increasing of arterial stiffness is a complex process reflecting of arterial health and which associated with atherosclerosis development and progression in the different parts of arterial tree [20,21]. Arterial stiffening is also associated with progression of target organ damage, such as renal damage, retinopathy, myocardial and skeletal muscles hypoperfusion [22-24]. In current hypertension guidelines arterial stiffness considered as a predictor of cardio-vascular events [25-30], such as myocardial infarction, stroke and heart failure independently from other traditional risk factors, including arterial hypertension [31].

A lot of risk factors and pathophysiological mechanisms linking arterial stiffening to cardio-vascular disease are present in patients with OSA (including obesity and $\mathrm{AH}$ ). Parameters or arterial stiffness help to stratify patients with low or high cardio-vascular risk when added to traditional risk factors and to reveal patients with suspicion of subclinical target organ damage [32-34].

Therefore, increased arterial stiffness may play a role in the risk elevation of cardiovascular complications in OSA patients. Early diagnostics of arterial stiffening allows predict clinical target organ damage by modification of cardio-vascular risk factors. And assessment of arterial stiffness in patients with $\mathrm{AH}$ and OSA may be an effective method to monitor disease progression and treatment efficacy.

There are some studies to estimate arterial stiffness in OSA patients, but their results are inconsistent because they included different patients. Consider the high prevalence of OSA among patients with arterial hypertension we selected patients with diagnosed essential arterial hypertension.

Thus, in the study of A. Noda et al. were shown, that augmentation pressure $(\mathrm{AuP})$ and the Aix were significantly greater in OSA patients than in controls $(9.0 \pm 4.1$ vs. $6.4 \pm 3.4 \mathrm{~mm} \mathrm{Hg}, \mathrm{P}<0.001 ; 23.5 \pm 8.7$ vs. $18.6 \pm 9.0 \%, \mathrm{P}=0.020$, respectively). AuP was also significantly greater in hypertensive $(11.4 \pm 3.5 \mathrm{~mm} \mathrm{Hg}, \mathrm{n}=14, \mathrm{P}<0.001)$ or normotensive $(7.9 \pm 3.9 \mathrm{~mm} \mathrm{Hg}, \mathrm{n}=31, \mathrm{P}=0.013)$ OSA patients than in control subjects; in addition, it was significantly greater in hypertensive OSA patients than in normotensive OSA patients $(\mathrm{P}=0.032)$. And AuP was significantly reduced in 19 OSA patients treated with CPAP-therapy [35]. In such a manner, in this study were comparable hypertensives with normotensive patients, as distinguished from our study, where all included patients were hypertensive.

In the study of Claudia E. Korcarz were shown that patients with and without OSA had similar brachial, central aortic systolic (122.8 [15.1] vs. 119.1 [11.8] $\mathrm{mm} \mathrm{Hg}, \mathrm{P}=0.100)$ and diastolic blood pressures (77.1 [9.4] vs. 77.4 [8.6] mm Hg, $\mathrm{P}=0.834)$, and aortic PWV (9.06 [2.15] vs. $8.51[1.88] \mathrm{m} / \mathrm{s}$; all $\mathrm{P}>0.10$ ), likely because $61.2 \%$ of subjects with OSA and $32.5 \%$ of subjects without OSA were taking antihypertensive medications $(\mathrm{P}=0.014)$. Furthermore, on average, subjects with sleep disordered breathing had mild OSA (17.6 [16.2] vs. 2.2 [1.3] events $\left.\mathrm{h}^{-1}\right)$. There had drown conclusion that adverse effects of nocturnal oxygen desaturation on PWV was seen among normotensive individuals and was amplified with aging [36].

In our study the patients with $\mathrm{AH}$ and OSA in comparison with those without OSA had significantly higher PWVcf and central CSBP and we observe a worsening of those parameters during 10 months without proper treatment.

OSA defined as "modifiable" risk factors, and increased arterial stiffness is one of the mechanisms of its unfavorable effects.
Drager et al. randomly assigned 24 patients with severe OSA without comorbidities to receive no treatment or CPAP-therapy for 4 months. After this period of CPAP treatment, they found a significant decrease of arterial stiffness as assessed by PWV (10.4 \pm 1.0 vs. $9.3 \pm 0.9$ $\mathrm{m} \mathrm{s}^{-1} ; \mathrm{P}<0.001$ ) [37].

Kohler et al. in another randomized clinical trial (RCT) reported that AIx significantly decreased from $14.5 \%$ to $9.1 \%$ in patients with moderate to severe OSA after 4 weeks of CPAP treatment compared to sham CPAP [38]. In contrast, Jones et al. did not find a significant decrease of $\operatorname{AIx}(15.5 \% \pm 11.9 \%$ vs. $16.6 \% \pm 11.7 \%$; $\mathrm{P}=0.08)$ in 43 patients with an AHI $>15 \mathrm{~h}^{-1}$ after 12 weeks of CPAP or sham-CPAP treatment in their RCT. An important limitation of this study and possibly the reason why there was no significant effect of CPAP on AIx in the latter study was the very low adherence to CPAP therapy - only 3 hours per night [39].

In our study combination of CPAP-therapy and drug treatment supported the achievement of target office blood pressure level in contrast with OSA patients without CPAP-therapy. Therefore, if magnitude of systolic BP reduction in observed in our study still be sustained for the long period, it might improve prognosis in patients with arterial hypertension.

The present study added new data to considerations of the potential significance of OSA and its treatment with CPAP in patients with arterial hypertension. Firstly, our data confirmed that OSA contributed to higher cardio-vascular risk in patients with arterial hypertension via negative cardio-metabolic profile and increased arterial stiffness. Secondly, our data shown that the long-term therapy with CPAP in combination with antihypertensive treatment reduced arterial stiffness and promoted achievement good blood pressure control. Thirdly, OSA even of mild degree contributed the progression of arterial stiffening and hindered with achievement of target blood pressure level despite antihypertensive treatment in patients with arterial hypertension.

In view of that, these results may have clinically relevant significance and could have an important economic impact for health care system because the high prevalence of obstructive sleep apnea in patients with arterial hypertension $[1,2]$.

The strengths of our study are recruitment of sufficient patient's sample size, 10 month of follow-up with and without CPAP-therapy, inclusion of selected patients without comorbidities as usually be observed in hypertensive patients and the generalizability of the trial findings.

This study had several potential limitations. First, it was single center pilot study. Secondly, patients in CPAP-therapy subgroup showed slightly more severe OSA at baseline, as measured by AHI, lower $\mathrm{SaO}_{2}$ and higher daytime sleepiness than subgroup without OSA.

\section{Conclusions}

1. The presence of OSA in hypertensive patients associated with increase in arterial stiffness and level of central systolic blood pressure and related to more difficulties in achievement of target blood pressure level with conventional drug treatment.

2. Patients with arterial hypertension and OSA had higher fasting glucose and uric acid level and higher degree of cardio-vascular risk.

3. The combination of CPAP therapy with antihypertensive treatment in patients with arterial hypertension and moderate to severe OSA improved achievement of target blood pressure and had favorable effect on arterial elasticity and level of central BP. 
Sirenko Y (2020) Association between arterial stiffness and obstructive sleep apnea in patients with arterial hypertension and continuous positive airway pressure therapy

4. Nonetheless, our results indicated that OSA had negative impact on arterial stiffness.

\section{References}

1. Somers VK, White DP, Amin R, Abraham WT, Costa F et al. (2008) Sleep apnea and cardiovascular disease: an American Heart Association/American College Of Cardiology Foundation Scientific Statement from the American Heart Association Council for High Blood Pressure Research Professional Education Committee, Council on Clinical Cardiology, Stroke Council, and Council On Cardiovascular Nursing. In collaboration with the National Heart, Lung, and Blood Institute National Center on Sleep Disorders Research (National Institutes of Health). Circulation 118: 1080-1111. [Crossref]

2. Peppard PE, Young T, Barnet JH, Palta M, Hagen EW, et al. (2013) Increased prevalence of sleep-disordered breathing in adults. Am J Epidemiol 177: 1006-1014. [Crossref]

3. Pedrosa RP, Drager LF, Gonzaga CC, Sousa MG, de Paula LK, et al. (2011) Obstructive sleep apnea: the most common secondary cause of hypertension associated with resistant hypertension. Hypertension 58: 811-817. [Crossref]

4. Floras JS (2014) Sleep apnea and cardiovascular risk. J Cardiol 63: 3-8. [Crossref]

5. Baguet JP, Nadra M, Barone-Rochette G, Ormezzano O, Pierre H, et al. (2009) Early cardiovascular abnormalities in newly diagnosed obstructive sleep apnea. Vasc Health Risk Manag 5: 1063-1073. [Crossref]

6. Kaynak D, Göksan B, Kaynak H, Degirmenci N, Daglioglu S (2003) Is there a link between the severity of sleep-disordered breathing and atherosclerotic disease of the carotid arteries? Eur J Neurol 10: 487-493. [Crossref]

7. Baguet JP, Hammer L, Lévy P, Pierre H, Launois S, et al. (2005) The severity of oxygen desaturation is predictive of carotid wall thickening and plaque occurrence. Chest 128 : 3407-3412. [Crossref]

8. Drager LF, Bortolotto LA, Lorenzi MC, Figueiredo AC, Krieger EM, et al. (2005) Early signs of atherosclerosis in obstructive sleep apnea. Am J Respir Crit Care Med 172 613-618. [Crossref]

9. Tsioufis C, Thomopoulos K, Dimitriadis K, Amfilochiou A, Tousoulis D, et al. (2007) The incremental effect of obstructive sleep apnoea syndrome on arterial stiffness in newly diagnosed essential hypertensive subjects. J Hypertens 25: 141-146. [Crossref]

10. Protogerou AD, Laaban JP, Czernichow S, Kostopoulos C, Lekakis J, et al. (2008) Structural and functional arterial properties in patients with obstructive sleep apnoea syndrome and cardiovascular comorbidities. J Hum Hypertens 22: 415-422. [Crossref]

11. Epstein LJ, Kristo D, Strollo PJ Jr, Friedman N, Malhotra A, et al. (2009) Clinical guideline for the evaluation, management and long-term care of obstructive sleep apnea in adults. J Clin Sleep Med 5: 263-276. [Crossref]

12. Collop NA, Anderson WM, Boehlecke B, Claman D, Goldberg R, et al. (2007) Clinical guidelines for the use of unattended portable monitors in the diagnosis of obstructive sleep apnea in adult patients. Portable Monitoring Task Force of the American Academy of Sleep Medicine. J Clin Sleep Med 3: 737-747. [Crossref]

13. Mancia G, Fagard R, Narkiewicz K, Redo'n J, Zanchetti A, et al. (2013) 2013 ESH/ ESC Guidelines for the management of arterial hypertension. TheTask Force for the management of arterial hypertension of the European Society of Hypertension (ESH) and of the European Society of Cardiology (ESC). J Hypertens 31: 1281-1357. [Crossref]

14. Johns MW (1991) A new method for measuring daytime sleepiness: the Epworth Sleepiness Scale. Sleep 14: 540-545. [Crossref]

15. Iber C, Ancoli-Israel S, Chesson AL, QuranSF (2007) The AASM manual for the scoring of sleep and associated events: rules, terminology and technical specifications. Westchester, IL: American Academy of Sleep Medicine.

16. Kapur VK, Auckley DH, Chowdhuri S, Kuhlmann DC, Mehra R, et al. (2017) Clinical Practice Guideline for Diagnostic Testing for Adult Obstructive Sleep Apnea: An American Academy of Sleep Medicine Clinical Practice Guideline. J Clin Sleep Med 13: 479-504. [Crossref]

17. SphygmoCor; AtCor Medical, Sydney, Australia (www.atcormedical.com).

18. Chen CH, Nevo E, Fetics B, PH Pak, FC Yin, et al. (1997) Estimation of central aortic pressure waveform by mathematical transformation of radial tonometry pressure validation of generalized transfer function. Circulation 95: 1827-1836. [Crossref]

19. Lang RM, Bierig M, Devereux RB, Flachskampf FA, Foster E, et al. (2006) Recommendations for chamber quantification. Eur $J$ Echocardiogr 7: 79-108 [Crossref]
20. Dustan HP (1999) 50th anniversary historical article: hypertension. J Am Coll Cardiol 33: 595-597. [Crossref]

21. Cruickshank JK, Rezailashkajani M, Goudot G (2009) Arterial stiffness, fatness, and physical fitness: ready for intervention in childhood and across the life course? Hypertension 53: 602-604. [Crossref]

22. Ikonomidis I, Lekakis J, Papadopoulos C, Triantafyllidi H, Paraskevaidis I, et al (2008) Incremental value of pulse wave velocity in the determination of coronary microcirculatory dysfunction in never-treated patients with essential hypertension. $\mathrm{Am}$ J Hypertens 21: 806-813. [Crossref]

23. Triantafyllidi H, Arvaniti C, Lekakis J, Ikonomidis I, Siafakas N, et al. (2009) Cognitive impairment is related to increased arterial stiffness and microvascular damage in patients with never-treated essential hypertension. Am J Hypertens 22: 525530. [Crossref]

24. Mule G, Cottone S, Vadala A, Volpe V, Mezzatesta G, et al. (2004) Relationship between albumin excretion rate and aortic stiffness in untreated essential hypertensive patients. J Intern Med 256: 22-29. [Crossref]

25. Roman MJ, Devereux RB, Kizer JR, Lee ET, Galloway JM, et al. (2007) Central pressure more strongly relates to vascular disease and outcome than does brachial pressure: the Strong Heart Study. Hypertension 50: 197-203. [Crossref]

26. Mitchell GF, Hwang SJ, Vasan RS, Larson MG, Pencina MJ (2010) Arterial stiffness and cardiovascular events: the Framingham heart study. Circulation 121: 505-511. [Crossref]

27. Willum-Hansen T, Staessen JA, Torp-Pedersen C, Rasmussen S, Thijs L, et al. (2006) Prognostic value of aortic pulse wave velocity as index of arterial stiffness in general population. Circulation 113: 664-670. [Crossref]

28. Inoue N, Maeda R, Kawakami H, Shokawa T, Yamamoto H, et al. (2009) Aortic pulse wave velocity predicts cardiovascular mortality in middle-aged and elderly Japanese men. Circ J 73: 549-553. [Crossref]

29. Laurent S, Alivon M, Beaussier H, Boutouyrie P (2012) Aortic stiffness as a tissue biomarker for predicting future cardiovascular events in asymptomatic hypertensive subjects. Ann Med 1: S93-97. [Crossref]

30. Muiesan ML, Salvetti M, Paini A, Monteduro C, Rosei CA (2010) Pulse wave velocity and cardiovascular risk stratification in a general population: the Vobarno study. $J$ Hypertens 28: 1935-1943. [Crossref]

31. Mattace-Raso FU, van der Cammen TJ, Hofman A, van Popele NM, Bos ML, et al (2006) Arterial stiffness and risk of coronary heart disease and stroke: the Rotterdam study. Circulation 113: 657-663. [Crossref]

32. Redfield MM, Jacobsen SJ, Borlaug BA, Rodeheffer RJ, Kass DA (2005) Age- and gender-related ventricular-vascular stiffening: a community-based study. Circulation 112: 2254-2262. [Crossref]

33. Ikonomidis I, Lekakis J, Stamatelopoulos K, Markomihelakis N, Kaklamanis PG, et al (2004) Aortic elastic properties and left ventricular diastolic function in patients with Adamantiades-Behcet's disease. J Am Coll Cardiol 43: 1075-1081. [Crossref]

34. Eren M, Gorgulu S, Uslu N, Celik S, Dagdeviren B, et al. (2004) Relation between aortic stiffness and left ventricular diastolic function in patients with hypertension, diabetes, or both. Heart 90: 37-43. [Crossref]

35. Noda A, Nakata S, Fukatsu H, Yasuda Y, Miyao E, et al. (2008) Aortic pressure augmentation as a marker of cardiovascular risk in obstructive sleep apnea syndrome. Hypertens Res 31: 1109-1114. [Crossref]

36. Korcarz CE, Gepner AD, Peppard PE, Young TB, Stein JH (2010) The Effects of SleepDisordered Breathing on Arterial Stiffness are Modulated by Age. Sleep 33: 1081-1085. [Crossref]

37. Drager LF, Bortolotto LA, Figueiredo AC, Krieger EM, Lorenzi GF (2007) Effects of continuous positive airway pressure on early signs of atherosclerosis in obstructive sleep apnea. Am J Respir Crit Care Med 176: 706-712. [Crossref]

38. Kohler M, Pepperell JC, Casadei B, Craig S, Crosthwaite N, et al. (2008) CPAP and measures of cardiovascular risk in males with OSAS. Eur Respir J 32: 1488-1496. [Crossref]

39. Jones A, Vennelle M, Connell M, McKillop G, Newby DE, et al. (2013) The effect of continuous positive airway pressure therapy on arterial stiffness and endothelial function in obstructive sleep apnea: a randomized controlled trial in patients without cardiovascular disease. Sleep Med 14: 1260-1265 [Crossref]

Copyright: (C2020 Sirenko Y. This is an open-access article distributed under the terms of the Creative Commons Attribution License, which permits unrestricted use, distribution, and reproduction in any medium, provided the original author and source are credited. 